\title{
PROBLEMAS DOS PACIENTES DE UNIDADE DE TERAPIA INTENSIVA: ESTUDO COMPARATIVO ENTRE PACIENTES E ENFERMEIROS*
}

Miako Kimura**

KIMURA, M. Problemas dos pacientes de Unidade de $I$ e 1 apia Intensiva: estudo comparativo entre pacientes e enfermeiros. Rev. Esc. Enf. USP, Săo Paulo, 22(2):169-179, ago. 1988.

Trata-se de trabalho em que se invesitiou os problemas prioritários dos pacientes internados em Unidades de Terapia Intensiva (UTIs), de urordo com sua percepçao e a dos enfermeiros que as assistem. Os problemas indicados por ambos os gi upos (pacientes e enfermeiros) foram analisados comparativamente segundo sua natureza, valorızaçdo atribuida uns mesmos e influência do grau de comprometimento flsico dos pacientes nessa valorizaçdo.

UNITERMOS: Unidade de Ierapia intensiva. Paciente hospitalizado. Problemas do paciente.

\section{INTRODUÇÃO}

Ao analisarmos diferentes trabalhos que objetivaram conhecer os problemas prioritários sentidos por individuos hospitalizados, observamos que a grande maioria baseia-se no levantamento destes problemas tendo, como referência, a percepção dos pacientes; quase unanimemente, estes estudos enfatizam a necessidade de que o enfermeiro leve em consideração, no planejamento da assistência de enfermagem, os problemas que o paciente sente como prioritários.

Contudo, muitos destes estudos não fazem referência aos problemas que o enfermeiro identifica como os mais importantes para os pacientes e, consequentemente, poucos são os trabalhos evolvendo a percepção de problemas mencionados por pacientes e enfermeiros.

Partindo da premissa de que o enfermeiro deve planejar a assistência de enfermagem baseando-se primordialmente nas necessidades estabelecidas pelos seus assistidos, acreditamos que um estudo comparativo entre a opiniåo de pacientes e enfermeiros, quanto aos problemas respectivamente sentidos e identificados, seja de fundamental importância para a prática da enfermagem, pois, a qualidade da assistência prestada ao paciente irá depender, em grande parte, da correta identificação dos problemas mais sentidos e da correspondência, entre pacientes e enfermeiros, de valorizaçăo atribuida a esses problemas.

\footnotetext{
- Resumo da Dissertaçåo de Mestrado apresentada à Escola de Enfermagem da USP. Săo Paulo, 1984.

* Enfermeira. Mestre em Enfermagem. Professora Ässistente do Departamento de Enfermagem Médico-Cirúrgica da Escola de Enfermagem da USP - disciplina Enfermagem Médico-Cirúrgica.
} 
Para a realizaçào de trabalho desta natureza julgamos que as Unidades de Terapia Intensiva - UTIs - seriam locais adequados, uma vez que é preconizada a presença de pelo menos um enfermeiro responsável pela assistência de enfermagem durante as $24 \mathrm{~h}$ do dia, e nelas os pacientes constituem uma população submetida a uma situação característica semelhante.

A despeito desta relativa uniformidade e semelhança nos aspectos da gravidade e criticidade da situação, observa-se, nas UTIs, que o comprometimento físico dos pacientes atinge diferentes niveis podendo ser este um fator capaz de influenciar diretamente a maneira de como pacientes e enfermeiros percebem e valorizam os problemas decorrentes da internação em UTI.

Assim, os objetivos deste trabalho foram:

1. investigar a natureza dos problemas prioritários sentidos pelos pacientes internados em UTI e a dos identificados pelos enfermeiros que os assistem;

2. estudar comparativamente os problemas prioritários sentidos pelos pacientes internados em UTl e os identificados pelos enfermeiros que os assistem, quanto à sua natureza e o valor que lhes é dado;

3. verificar se, na valorização desses problemas, os pacientes internados em UTI e os enfermeiros que os assistem sofrem a influência da quantidade de procedimentos invasivos a que os primeiros estão submetidos.

\section{METODOLOGIA}

Fizeram parte do estudo 100 pacientes e 45 enfermeiros de 6 UTIs de um mesmo hospital, campo da pesquisa.

Os pacientes, todos com 2 a 4 dias de permanência da UTI, eram adultos de ambos os sexos, brasileiros natos ou naturalizados, conscientes, orientados no tempo e no espaço e em condiçōes de serem entrevistados.

A seleção dos enfermeiros para o estudo será descrita mais adiante.

Por se tratar de pesquisa de percepção de problemas, procuramos considerar as interaçỏes entre pacientes e enfermeiros, pois, como se sabe, a percepção é um fenômeno extremamente subjetivo, podendo, variar de pessoa para pessoa. Como cada paciente, durante a sua permanência na UTI, interagia com vários enfermeiros que o assistiam nos diferentes plantōes, era importante obtermos o maior número possivel de respostas de enfermeiros a partir das quais obteríamos os problemas daquele paciente, considerados prioritários pelos enfermeiros.

Portanto, neste trabalho, consideramos como a população de estudo referente aos pacientes, a totalidade das respostas enunciadas por eles quanto aos seus problemas prioritários. Do mesmo modo, consideramos como a população de estudo referente aos enfermeiros, a totalidade das respostas enunciadas por eles quanto aos problemas que julgavam prioritários para os pacientes.

Convém lembrar que neste trabalho, foi considerado como problema tudo aquilo a que o paciente se referia (ou que o enfermeiro nele identificava) como coisas ou situações que o incomodavam ou das quais ele sentia falta.

Uma vez determinado o paciente, todos os enfermeiros que haviam mantido relacionamento com o mesmo, executando cuidados diretos ou supervisionando a assistência de enfermagem a ele prestada, eram incluídos em uma lista, numerada de 1 
a $n$. A seguir, pelo processo de amostragem sistemática, com intervalo 2, foram sorteados os enfermeiros que deveriam responder sobre os problemás prioritários daquele paciente.

Por esse processo obtivemos uma amostra equiprobabilistica de respostas emitidas pelos enfermeiros, relativas aos respectivos pacientes; assim, embora o número de enfermeiros fosse inferior ao de pacientes, ficou garantido que a cada paciente correspondesse, pelo menos uma resposta de enfermeiro, referente a seus problemas prioritários.

Os dados deste trabalho foram coletados em 2 formulários adaptados a partir do modelo elaborado por KAMIYAMA ${ }^{2}$ para o levantamento de problemas sentidos por pacientes hospitalizados em unidades médico-cirúrgicas, que, aliás, já fôra utilizado com pacientes de UTI por KOIZUMI et alii ${ }^{3}$ e PADILHAss.

\section{RESULTADOS E DISCUSSÃO}

Tanto os problemas sentidos pelos pacientes como os identificados pelos enfermeiros foram, inicialmente, classificados em níveis de prioridade, em ordem decrescente da importância a eles atribuída. Foi feita, a seguir, análise qualitativa e quantitativa dos mesmos, ou seja, foram analisados de acordo com a sua natureza e com a valorização dada a eles pelos grupos estudados de pacientes e enfermeiros. Consideramos a valorização dos problemas pela freqüência com que foram referidos e pela prioridade a eles atribuida.

\section{Natureza dos problemas prioritários indicados pelos pacientes e enfermeiros}

Os resultados obtidos mostraram que, de forma geral, os dois grupos indicaram problemas de paciente de natureza semelhante na $1^{a}$ e $2^{a}$. prioridades, os quais foram classificados em 15 categorias de problemas, relativos a: separação da família, dor, uso de sondas, drenos e catéteres, alimentação e hidratação, relacionamento interpessoal, medo do desconhecido, atividade e recreação, manobras para a eliminação da secreção pulmonar, ambiente, sintomatologia clínica, falta de liberdade, falta de objetos de uso pessoal, dependência de outrem, interrupção da atividade ocupacional e necessidade de cuidados e controles freqüentes.

Pela natureza dos problemas sentidos pelos pacientes e identificados pelos enfermeiros, pudemos verificar que, mesmo em condição de intensa ameaça à vida, o ser humano reage como um todo somato-psíquico e social, fato também ressaltado por outros autores.

Apesar desta grande gama de problemas levantados, alguns destacaram-se pela frequiência com que pacientes e enfermeiros os mencionaram.

Optamos, assim, por estudar de maneira mais profunda os quatro grupos de problemas mais freqüentemente mencionados, tanto por pacientes como por enfermeiros, pois pareceu-nos que estes eram realmente os mais significativos dentro daquela gama de problemas levantados. Reconhecemos, entretanto, que apesar de mencionados com menor freqüência, os demais problemas referidos pelos dois grupos são também importantes, uma vez que foram por eles considerados como problemas de 1 a e 2 ? prioridades. 


\section{NATUREZA DOS PROBLEMAS PRIORITÁRIOS}

Problemas mais freqüentemente indicados pelos pacientes

Em $1 .{ }^{a}$ prioridade

- separaçãò da familia

- dor

- sondas, drenos e catéteres

- alimentação e hidratação

Em $2 .{ }^{a}$ prioridade

- dor

- sondas, drenos e catéteres

- atividade e recreação

- ambiente

- separação da família
Problemas mais freqüentemente indicados pelos enfermeiros

\section{Em 1.: prioridade}

- separação da família

- ambiente

- dor

- sondas, drenos e catéteres

\section{Em 2.: prioridade}

- ambiente

- sondas, drenos e catéteres

- separação da família

- dor

Problemas como os causados pela separação da família, pela dor, pela presença de artefatos terapêuticos e os decorrentes de condiçðes ambientais foram percebidos tanto pelos pacientes como pelos enfermeiros. Já os referentes ao atendimento de necessidades básicas como a alimentação e hidratação e a atividade e recreação foram mais sentidos pelos pacientes, mas não foram incluidos pelos enfermeiros entre os 4 mais importantes.

De forma geral estes mesmos problemas foram semelhantes aos encontrados pelos diversos autores que investigaram problemas sentidos por pacientes em UTIs.

Foi, ainda, interessante notar que, em geral, os problemas mais mencionados pelos pacientes e enfermeiros guardavam certa semelhança entre si, no tocante à sua natureza; isto, talvez, porque a continua exposição à intensa problemática dos pacientes, proporcione aos enfermeiros de UTI oportunidade excepcional de observar reaç̋es, sentimentos e desejos de seus pacientes.

\section{Comparação entre pacientes e enfermeiros quanto à valorização dos problemas}

Ao estudarmos o valor atribuido por pacientes e enfermeiros aos problemas mais freqüentemente indicados, constatamos diferença estatisticamente significante entre ambos os grupos, tanto na $1^{\text {a }}$ como na 2 ? prioridade.

É interessante notar que a diferença observada na Tabela 1 não foi devida aos problemas de alimentação e hidratação, incluidos, apenas pelos pacientes, entre os quatro mais importantes; a maior discordância entre os dois grupos refere-se à valorização dos problemas relativos à separação da familia e ao ambiente, embora ambos os tenham percebido como prioritários. Os pacientes declararam sentir intensamente a separação da familia e os enfermeiros identificaram, como os mais importantes, os problemas inerentes ao ambiente da UTI. 
TABELA 1

OPINIÃO DE PACIENTES E ENFERMEIROS, SEGUNDO OS PROBLEMAS MAIS FREQÜENTEMENTE INDICADOS EM 1? PRIORIDADE.

\begin{tabular}{|c|c|c|c|c|c|c|}
\hline \multirow{2}{*}{ Problemas } & \multicolumn{2}{|c|}{ Pacientes } & \multicolumn{2}{|c|}{ Enfermeiros } & \multicolumn{2}{|c|}{ Total } \\
\hline & n? & $\%$ & n? & $\%$ & no & $\%$ \\
\hline $\begin{array}{l}\text { Relativos a: } \\
\text { separação da } \\
\text { famnlia }\end{array}$ & 52 & $(46,9)$ & 76 & $(34,5)$ & 128 & $(38,7)$ \\
\hline dor & 22 & $(19,8)$ & 47 & $(21,4)$ & 69 & $(20,8)$ \\
\hline ambiente & 7 & $(6,3)$ & 55 & $(25,0)$ & 62 & $(18,7)$ \\
\hline $\begin{array}{l}\text { sondas, drenos e } \\
\text { catéteres }\end{array}$ & 18 & $(16,2)$ & 29 & $(13,2)$ & 47 & $(14,2)$ \\
\hline $\begin{array}{l}\text { alimentação e } \\
\text { hidratação }\end{array}$ & 12 & $(10,8)$ & 13 & $(5,9)$ & 25 & $(7,6)$ \\
\hline TOTAL & 111 & $(100,0)$ & 220 & $(100,0)$ & 331 & $(100,0)$ \\
\hline$x^{2} g_{g l}=19,61$ & & & & & & $0.5 \%=$ \\
\hline
\end{tabular}

Para se compreender a importância relevante atribuida pelos pacientes à separação da familia, é interessante relatar que a população estudada foi constituída, principalmente, de individuos de faixa etária economicamente ativa, com grande proporção de chefes de família de baixo nível sócio-econômico. Pela condição de enfermos graves internados na UTI, ambiente em que há conotação de morte iminente, é possivel avaliar a grande preocupaçăo desses pacientes, não somente com a sua sobrevivência, mas, também, com as repercussðes do seu estado de saúde para todos os seus dependentes.

Para alguns pacientes entrevistados, a separaçăo da familia foi mencionada como uma sensaçåo desagradável, presente constantemente, tanto na permanência em enfermarias, como em UTI. Outros, mesmo com grande sofrimento físico, chegaram a afirmar que, para eles, a única coisa que realmente incomodava era a preocupação com a familia.

Esses fatos parecem evidenciar que a manifestação de problemas relacionados à familia independe da condição física e do local de internação dos pacientes. Só o fato de estarem confinados no ambiente hospitalar, seja qual for a unidade de internação, é suficiente para determinar a manifestação de tais problemas, podendo ocasionar, nos pacientes, sentimentos de solidão e abandono.

A falta de concordância entre as opiniōes dos dois grupos acentua-se em relação ao ambiente, muito valorizado pelos enfermeiros, porém, proporcionalmente menos significativo para os pacientes.

$\mathrm{Na}$ UTI, a atuação do enfermeiro pressupõe intensa atividade física e elevado grau de estresse emocional, conseqüente ao contato permanente com situaçðes de vida ou morte do paciente, com a ansiedade dos familiares, além de sua própria expec- 
tativa, e da expectativa da equipe médica e dos pacientes, quanto à sua eficiência no desempenho profissional.

Estando os enfermeiros submetidos a angústias e tensōes inerentes ao seu ambiente de trabalho, poder-se-ia levantar a hipótese de que a preocupação com os fatores ambientais, que identificaram como sendo dos pacientes, possa ser uma projeção de sua própria ansiedade em face dessa situação.

De certa forma, os problemas mais referidos por pacientes e enfermeiros na 1. prioridade estão intimamente ligados ao confinamento no ambiente da UTI. Para os pacientes, tal confinamento é percebido como a separaçăo da familia e, para os enfermeiros, como sofrimento dos pacientes devido ao ambiente físico da UTI.

TABELA 2

OPINIĀo DE PACIENTES E ENFERMEIROS, SEGUNDO OS PROBLEMAS MAIS FREQÜENTEMENTE INDICADOS EM 2? PRIORIDADE.

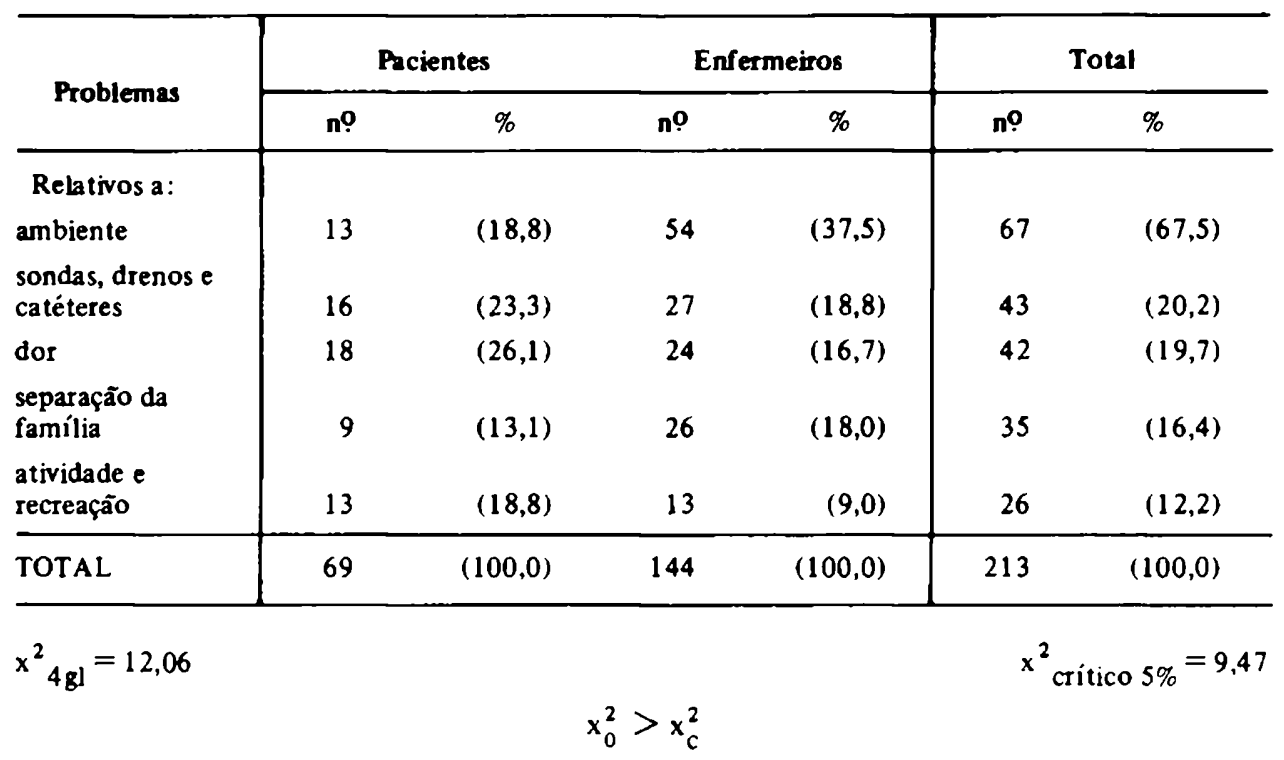

A diferença estatisticamente significante entre pacientes e enfermeiros, quanto aos problemas de 2. prioridade, resultou da maneira discordante com que estes grupos valorizaram problemas percebidos de forma coincidente, quais sejam, os referentes ao ambiente e à dor. Os primeiros foram, novamente, mais considerados pelos enfermeiros e os últimos, mais valorizados pelos pacientes. A falta de atividade e recreação, indicada neste nivel de prioridade somente pelos pacientes, entre os quatro mais sentidos, foi confirmada como um problema discordante.

A grande freqüência com que o "ambiente" da UTI foi apontada pelos enfer-

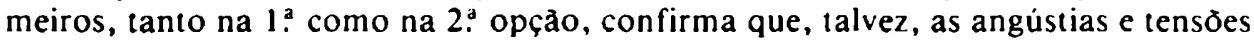
inerentes a ele tenham significado, para estes profissionais, um duplo sofrimento. Primeiro, porque estảo constantemente sujeitos ao clima de agressividade psicológica daquele ambiente, bem como ao peso de um árduo trabalho e, segundo, porque, de certa forma, são eles que sujeitam o paciente àquelas condiçoes, consideradas al- 
tamente indesejáveis e traumatizantes, o que, segundo MOCAVERO et alii`, pode desenvolver grave sentimento de culpa.

Diante do exposto, acredita-se que, no tocante aos problemas concernentes ao ambiente, é de fundamental importância que se leve em consideraçăo não só o bem-estar do paciente, mas também o do enfermeiro, visto que é deste profissional que irá depender grande parte da qualidade da assitência que o paciente receberá. Se o estresse do enfermeiro nåo lhe permitir a melhor atuação possivel, no sentido profissional e pessoal, ele estará, como afirma VIEIRA', constantemente ameaçado de certo grau de ansiedade, que poderá levá-lo à frustração, ponto de partida para o desinteresse profissional.

Enquanto a preocupaçào dos enfermeiros estava muito mais dirigida para aspectos ambientais, os pacientes do presente estudo sentiam a dor como um dos problemas mais importantes.

Isto é perfeitamente compreensível, tendo em vista os diversos procedimentos traumatizantes a que eles foram submetidos, tais como drenagem torácica, intubação traqueal, sondagem vesical e nasogástrica, entre outriss, além de numerosas feridas cirúrgicas.

Como se sabe, a dor tem a sua origem fundamentialmente na parte física e sensível do ser, porém ela pode adquirir também uma dinı'nsão psíquica, aumentando, em proporçðes diversas, o sofrimento inicial.

Sendo este um sintoma que ocorre com grande frequência entre os enfermos, é função primordial da equipe de saúde prestar-lhes assistência individualizada, que contribua para o seu conforto, compreendendo-a como uma experiência subjetiva, que envolve o ser humano como um todo.

Os resultados mostram, ainda, que os problemas referentes a atividade e recreação foram sentidos como prioritários pelos pacientes, porém năo valorizados na mesma proporção pelos enfermeiros.

A manifestação de descontentamento quanto à impossibilidade e dificuldade de movimentação é justificável, em se tratando de pacientes em estado crítico, acamados e dependentes, como os da presente investigação. Para muitos deles, mesmo a execução de movimentos aparentemente simples, como o mudar de posição no leito, era extremamente penosa, dada a precariedade de suas condiçðes físicas, além da dor e da presença de artefatos inseridos no seu corpo.

Autores como VIEIRA ${ }^{\circ}$ e ASHWORTH' afirmam que a dificuldade ou impossibilidade de executar movimentos corporais é fonte de privação sensorial, que pode a fetar o equilibrio psicológico do indivíduo em graus variáveis. Talvez o estímulo da movimentação e da atividade física recomendada aos pacientes tenha o efeito de previnir, não somente complicaçðes circulatórias e respiratórias, como também distúrbios emocionais.

À primeira vista pode parecer estranho que pacientes em regime de tratamento intensivo tenham levantado como problema a falta de recreação; porem, a sua indicação faz supor que a própria condição de inatividade e imobilidade, já menciona$\mathrm{da}$, os tenha levado a desejar uma estimulação mais rica e variada. Talvez esta seja um importante meio para o alívio de tensðes emocionais, contribuindo para o bem-estar mental do paciente.

Constatamos, portanto, que, na $2:$ prioridade, enquanto os pacientes se preocupavam mais com os problemas concernentes à dor, à atividade e à recreaçăo, os enfermeiros continuaram a valorizar os decorrentes do ambiente. 
Influência dos procedimentos invasivos sobre os problemas prioritários indicados pelos pacientes e enfermeiros.

Os pacientes de UTI, em geral, sejam jovens, adultos, homens ou mulheres, caracterizam-se por estar sujeitos a grande número de procedimentos invasivos devido ao próprio estado crítico em que se encontram.

A grande maioria dos pacientes deste estudo apresentava feridas cirúrgicas e, de certa forma, dependia de aparelhos e de procedimentos outros para manutenção e controle de suas funçðes vitais, bem como para previnir o aparecimento de intercorrências.

Os pacientes com 1 a 6 procedimentos invasivos foram considerados, neste estudo, como os menos agredidos $(60 \%)$ e aqueles com maior número deles, ou seja, de 7 a 15 , foram considerados os mais agredidos $(40 \%)$.

Embora se tenha verificado inicialmente que os problemas indicados por pacientes e enfermeiros foram coincidentes quanto à sua natureza, constatamos diferença estatisticamente significante entre a opinião de pacientes e enfermeiros quanto à valorização dos quatro problemas mais freqüentemente citados.

Para verificarmos se esta diferença constatada era influenciada pelo grau de agressão física a que estavam submetidos os pacientes, aplicamos, novamente, o teste da associação $\left(x^{2}\right)$. A comparação foi feita entre pacientes com menor e maior quantidade de procedimentos invasivos, bem como entre a opiniåo de enfermeiros que sobre eles responderam.

Considerando que os pacientes internados em UTI podem experimentar diferentes niveis de traumatismos físicos, supúnhamos que estes seriam indicadores importantes para diferenciar a maneira de perceber seus problemas. Entretanto, esta suposição não foi confirmada pois não foi verificada diferença estatisticamente significante na valorizaçào dos problemas sentidos pelos pacientes menos e mais agredidos fisicamente, tanto na 1 : como na $2^{a}$ : prioridade. Isto demonstra que, na verdade, o que predomina é o paciente como um todo e não o número de procedimentos invasivos a que é submetido.

Os problemas relativos à separação da familia foram os de maior significado para os pacientes, independente do seu comprometimento físico.

A manifestação de problemas referentes à dor e à presença de sondas, drenos e catéteres não guardou relação com a quantidade de procedimentos invasivos, tendo sido aqueles valorizados igualmente pelos pacientes com menos ou mais procedimentos invasivos.

Quanto aos enfermeiros, houve diferença estatisticamente significante na identificação dos problemas, de acordo com o grau de comprometimento físico dos pacientes, nas duas prioridades consideradas.

Para os pacientes com menor número de procedimentos invasivos foram identificados mais freqüentemente os problemas relativos à separação da família e ao am. biente, ou seja, consequientes ao confinamento imposto aos pacientes. Para aqueles com maior número de procedimentos invasivos, foram considerados relevantes os problemas concernentes à sensação dolorosa e à presença de sondas, drenos e catéteres, isto é, problemas de ordem fisica que mais diretamente pareciam atingir os pacientes.

A identificação feita pelos enfermeiros, de problemas relativos à familia como mais significativos para os pacientes menos agredidos, pressupde atendimento psico-social precário em relação àqueles pacientes cujos problemas físicos já eram mais 
numerosos. É possivel que as condiçð̄es dos pacientes de maior agressão física tenham feito com que os enfermeiros se preocupassem mais com a manipulação e o controle dos diferentes artefatos neles inseridos do que propriamente com a assistência à pessoa do paciente.

Os resultados mostram, também, que o ambiente foi problema identificado, pelos enfermeiros, com maior freqüência, para os pacientes com menor número de procedimentos invasivos, nos dois niveis de prioridade. Talvez suponham que os pacientes submetidos a menor quantidade de agressðes estejam mais propensos à influência do que acontece ao seu redor.

Para os pacientes com maior grau de agressão física, os enfermeiros identificaram mais, como problemas, a dor e a presença de artefatos terapêuticos.

Este fato poderia estar relacionado à maior exigência de atuação do enfermeiro junto a estes pacientes, fazendo com que, obrigatoriamente, se aproximassem deles mais tempo, a fim de dispensar cuidados à grande quantidade de procedimentos a que estavam submetidos. Talvez, ainda, o sentimento de empatia dos enfermeiros estivesse mais dirigido a estes pacientes, dada a situação de maior comprometimento físico. Dessa forma, teriam tido maiores oportunidades para identificar os reais problemas destes pacientes.

Compartilhar com o paciente crítico a condição de vida e morte, de grande insegurança emocional e dor, pode ser uma experiência extremamente rica, tanto para o paciente como para o enfermeiro. Exige, porém, deste profissional, não somente o conhecimento técnico-científico, mas um embasamento humanístico bem estruturado, que o torne capaz de compreender o paciente como pessoa em luta para superar sérias dificuldades.

A escassez de trabalhos específicos sobre a assistência de enfermagem ao paciente de UTI, bem como sobre as interaçðes do binômio enfermeiro-paciente, nessa Unidade, leva a sugerir a realização de outros estudos dirigidos a esse campo, para melhor atendimento da pessoa em estado crítico, que depende quase totalmente da equipe hospitalar para continuar a viver e que, como ser humano, experimenta todas as sensaçōes traumatizantes da dificil situação que vivencia.

\section{CONCLUSÃO}

Os resultados obtidos permitem as conclusðes que seguem:

1. Os problemas prioritários sentidos pelos pacientes e identificados pelos enfermeiros foram coincidentes quanto à sua natureza, tanto na $1^{\mathrm{a}}$ como na $2^{\mathrm{a}}$. prioridades. Os problemas foram categorizados em 15 grupos, relativos a separação da família, dor, sondas, drenos e catéteres, alimentação e hidratação, relacionamento interpessoal, medo do desconhecido, atividade e recreação, manobras para eliminação de secreção pulmonar, ambiente, sintomatologia clínica, falta de liberdade, falta de objetos de uso pessoal, dependência de outrem, interrupção da atividade ocupacional e necessidade de cuidados e controle frequientes.

2. Quanto à sua natureza, os grupos de problemas prioritários sentidos pelos pacientes, e identificados pelos enfermeiros com maior freqüência, foram parcialmente coincidentes nas duas prioridades consideradas: 
na 1. prioridade, as opiniōes de pacientes e enfermeiros coincidiram quanto à indicação dos problemas relativos à separação da família, dor, sondas, drenos e catéteres, diferindo quanto aos referentes a alimentação e hidratação, indicados apenas pelos pacientes, e quanto ao ambiente, indicados pelos enfermeiros entre os de maior freqüência;

- na 2. prioridade, os problemas coincidentes foram os mesmos mencionados na 1. prioridade, acrescidos dos ambientais e diferindo quanto aos concernentes à atividade e recreação, indicados, somente pelos pacientes, entre os mais freqüentes.

Quanto à valorização atribuida pelos pacientes e enfermeiros aos problemas prioritários de maior frequência, evidenciaram-se diferenças estatisticamente significantes:

- na 1. prioridade houve diferença na valorização dos problemas relativos à separação da familia e ao ambiente, sendo os primeiros mais valorizados pelos pacientes e os últimos, mais pelos enfermeiros;

- na 2. prioridade, enquanto os pacientes valorizaram mais os problemas referentes à dor e à atividade e recreaçăo, os enfermeiros, novamente, atribuiram maior valor aos problemas concernentes ao ambiente.

3. Os pacientes nảo sofreram influência da quantidade de procedimentos invasivos a que estavam submetidos, na valorização dos problemas prioritários mais freqüentemente indicados, o que foi evidenciado estatisticamente, tanto na 1. a como na 2: prioridade.

Os enfermeiros, por sua vez, sofreram a influência da quantidade de procedimentos invasivos a que estavam submetidos os pacientes, na valorização de problemas prioritários que neles identificaram em maior freqüência. Isto foi comprovado estatísticamente tanto na 1: como na 2: prioridade:

- para os pacientes com menor quantidade de procedimentos invasivos os enfermeiros valorizaram mais os problemas relativos à separação da família e ao ambiente;

para os pacientes com maior quantidade de procedimentos invasivos foram mais valorizados os problemas de dor e do uso de sondas, drenos e catéteres.

Assim sendo, os enfermeiros identificaram, com maior frequência, os problemas físicos nos pacientes com maior número de procedimentos invasivos, e os problemas decorrentes do confinamento imposto pelo ambiente da UTI, naqueles com menor número de procedimentos invasivos.

KIMURA, M. Problems of the patients in the Intensive Care Unities: a comparative study among patients and nurses. Rev. Esc. Enf. USP, 22(2):169-179, Aug. 1988.

The objective of this paper was to study the prioritary problems of the in patients of the Intensive Care Unities, according to their own perception and the nurses who care them. The problems indicated by both groups (patients and nurses) were analysed comparatively according to the nature, valuation attributed to them and influence of the degree of physical condition of the patients on this valuation.

UNITERMS: Intensive care unities. Hospitalized patient. Problem's patient. 


\section{REFERÊNCIAS BIBLIOGRÁFICAS}

1. ASHWORTH, P. Nursing care in the ICU. Nurs. Times, London, 77(25):1063-4, June 1981.

2. KAMIYAMA, Y. O doente hospitalizado e sua percepça quanto à prioridade de seus problemas. Săo Paulo, 1972, 111 p. (Tese de doutorado - Escola de Enfermagem da USP).

3. KOIZUMI, M.S.; KAMIYAMA, Y.; FREITAS, L.A. Percepção dos pacientes de UTI: problemas sentidos e expectativas em relaçào à assistência de enfermagem. Rev.Esc.Enf.USP, Såo Paulo, 13(2):135-45, ago. 1979.

4. MOCAVERO, G.; CUSIN, S.G.; CARLONI, C.; AZZARELlo, D. Problem psicologici in Terapia Intensiva. Min. Anest., Torino, 46 (supl. 5):629-48, ago. 1980.

5. PADILHA, K.G. Percepcão do coronariopata sobre o ambiente da Unidade de Terapia Intensiva. São Paulo, 1983. 63p. (Dissertaçăo de mestrado - Escola de Enfermagem da USP).

6. VIEIRA, T.T. Importância da imagem corporal na prática de enfermagem. Rio de Janeiro, 1976. 152p. (Tese de livre docência - Escola de Enfermagem Ana Neri da UFRJ).

Recebido para publicação em 24/3/87.

Aprovado para publicaçăo em 21/6/88. 